\title{
Design of Baffle and Slope for Hydraulic Characteristics of Vertical Slot Fishway
}

\author{
Xi Mao, Jiehao Zhang, Xinlan Liang*, Xiuyuan Lu, Yanping Tan, Min Yang, Keming Tang \\ College of Water Conservancy and Hydropower Engineering, Sichuan Agricultural University, Yaan, China \\ Email address: \\ maowhiteknight@163.com (Xi Mao), xinlanliang@hotmail.com (Xinlan Liang) \\ ${ }^{*}$ Corresponding author \\ To cite this article: \\ Xi Mao, Jiehao Zhang, Xinlan Liang, Xiuyuan Lu, Yanping Tan, Min Yang, Keming Tang. Design of Baffle and Slope for Hydraulic \\ Characteristics of Vertical Slot Fishway. American Journal of Physics and Applications. Vol. 5, No. 2, 2017, pp. 24-28. \\ doi: 10.11648/j.ajpa.20170502.13
}

Received: March 14, 2017; Accepted: March 27, 2017; Published: April 14, 2017

\begin{abstract}
The characteristics of the flow in vertical slot fishway depend mainly on the specific pool design, such as the geometry of the pool. We present the results of a study on comparison between four different designs of vertical slot fishways. The results indicated that central baffle cannot cut down the value of the velocity substantially, but it can stabilize the flow pattern, and it can make energy dissipation uniform. Simultaneously, slope has significant impact on hydraulic characteristics like velocity and flow pattern in the fishway. Of the four designs studied, design 4 is recommended for practical use, in terms of velocity and flow pattern.
\end{abstract}

Keywords: Fishway, Hydraulic Experiment, Baffle, Slope, Velocity, Flow Pattern

\section{Introduction}

Lots of hydropower stations had been built to meet the demand of electricity. These hydropower stations not only relieved the tension condition of electricity, but also had important significance to some problems such as flood control and ecology environment. However, fish populations were highly dependent on the characteristics of their aquatic habitat, since it provided the support for all their biological functions $[1,2]$. This dependency was more critical in the case of migratory fish which required different habitats to complete their life cycle; dam obstructed the normal migration of these migratory fish, and would give rise to destructive effect on the migratory fish [3]. Fishways are structures that facilitate the upstream or downstream migration of aquatic organisms over obstructions to migration such as dams and weirs. Fishways were generally studied under three types $[4,5]: 1)$ pool and weir fishways [6], 2) Denil fishways [7], and 3) vertical slot fishways [8]. The earliest vertical slot fishway was developed in about 1943 for use at Hell's Gate on the Fraser River in British Columbia, Canada [9]. The vertical slot fishway was constructed by installing baffles at certain spacing along a sloping rectangular channel to create a series of pools. The baffles were so shaped that part of the flow was turned back upstream to create recirculation regions in the pools where the fish would rest before ascending the fishway through the slots using their burst speed [10]. Water runs downstream through a series of vertical slots from one pool to the next; the water flow forms a jet at the slot and the flow energy is dissipated by jet mixing in the pools [11].

The characteristics of the flow in vertical slot fishways depended mainly on the specific pool design, such as the geometry of the pool. This paper conducted four different designs of vertical slot fishways with "I" or "L" shaped baffle (see Figure 1), and in two different slopes. The four different designs were: the first design (design 1, or original design), "I" shaped baffle, $S=5.4 \%$ ( $S$ denotes "slope"); the second design (design 2), "I" shaped baffle, $S=2.7 \%$; the third design (design 3 ), "L" shaped baffle, $S=5.4 \%$; the fourth design (design 4 ), "L" shaped baffle, $S=2.7 \%$.

Figure 1 showed the geometric characteristics of a pool with "I" or "L" shaped baffle. 


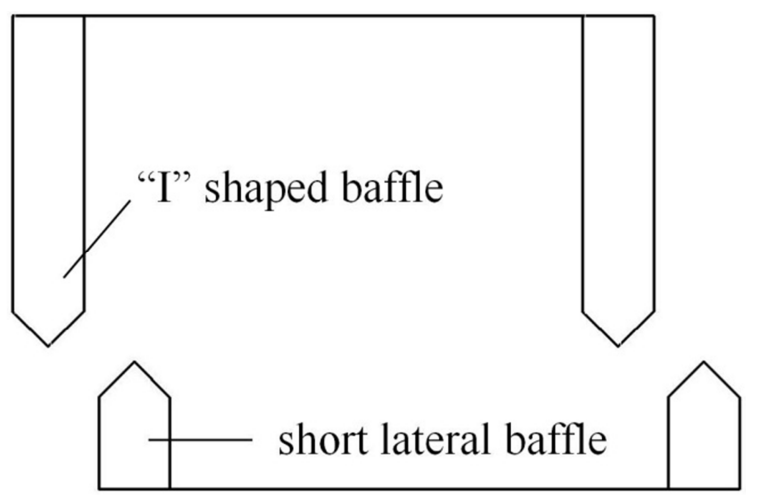

(a)

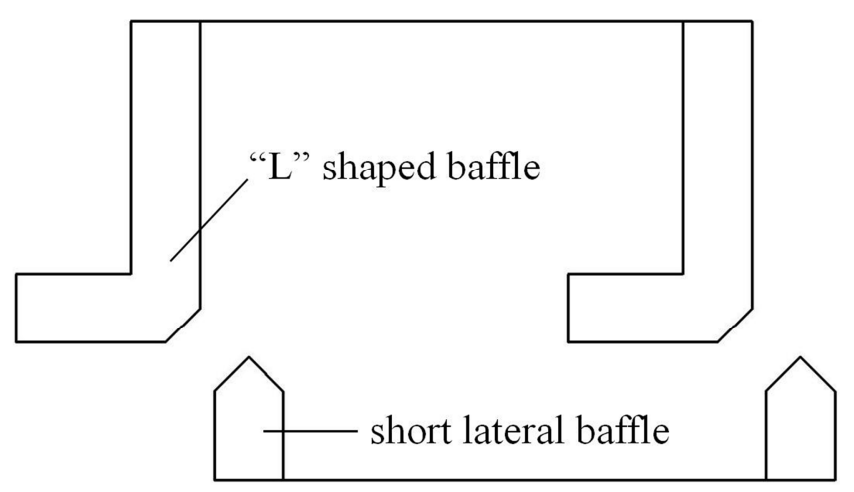

(b)

Figure 1. Geometric characteristics of a pool with (a) "I" shaped baffle;(b) "L" shaped baffle.

\section{Experimental Work}

Figure 2 showed photos of experimental work.

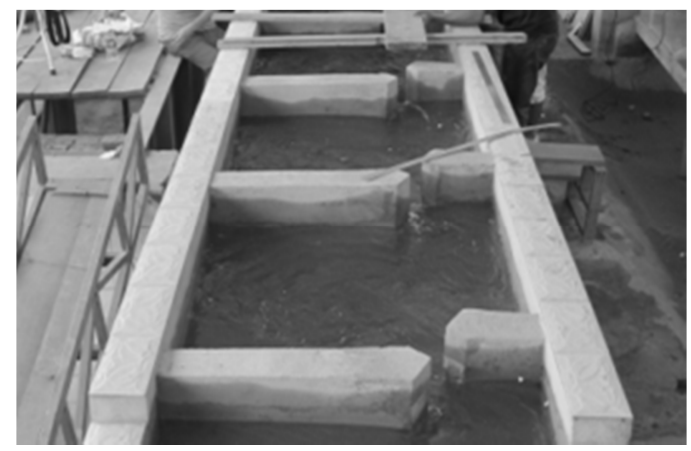

(a)

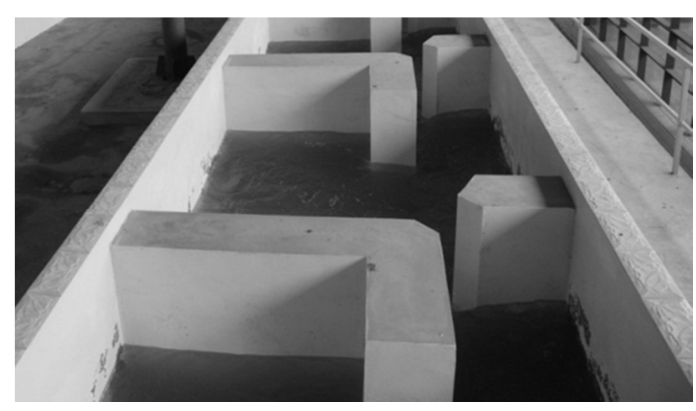

(b)

Figure 2. Photos of experimental work.
The size of vertical slot fishways with "I" shaped baffle (design 1\&2) are shown in Figure 3(a); and the size of vertical slot fishways with "L" shaped baffle (design 3 \& 4) are shown in Figure 3(b), where, $b$ is the slot width, $0.15 \mathrm{~m}$. The height of these four designs are the same, $\mathrm{H}=1.5 \mathrm{~m}$.

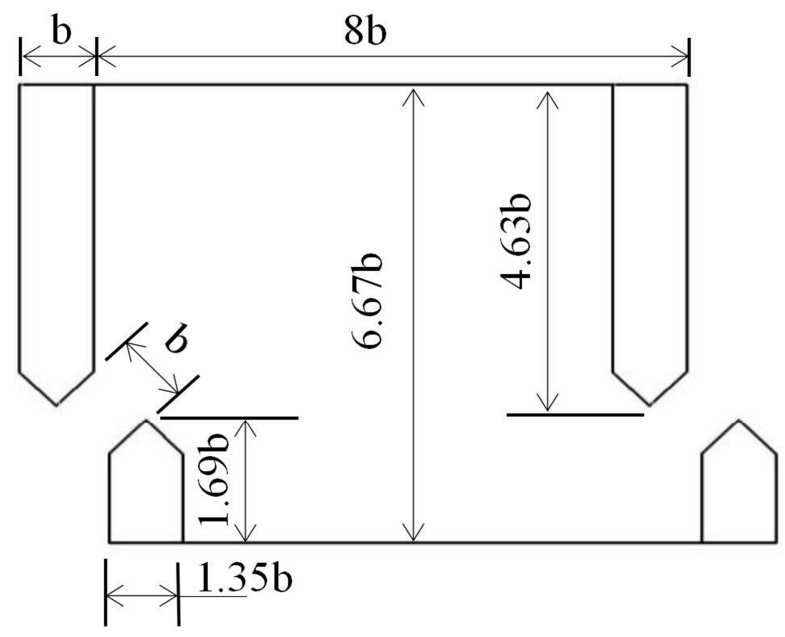

(a)

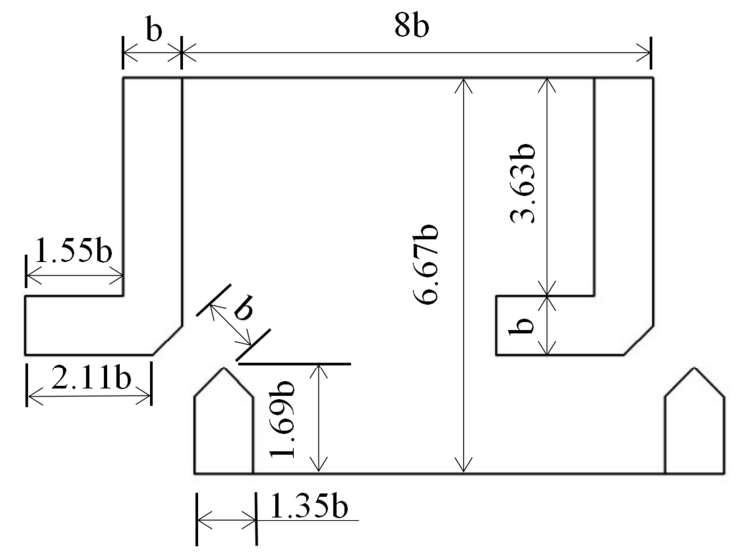

(b)

Figure 3. (a) Pool design with "I" shaped baffle; (b) Pool design with "L" shaped baffle.

\subsection{Experimental Work of Design 1}

The original design, "I" shaped baffle, $S=5.4 \%$ ( $S$ denotes "slope").

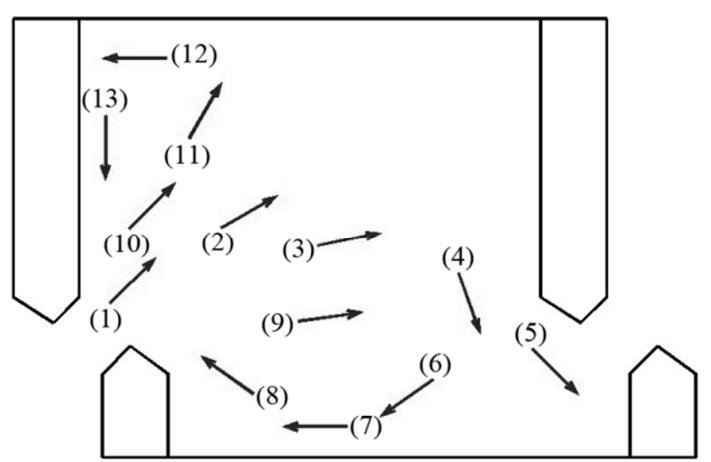

(a) 


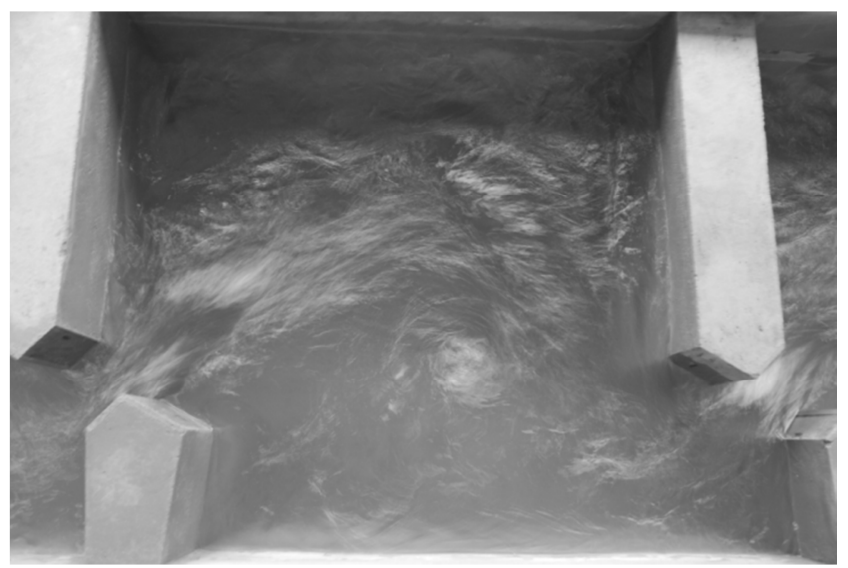

(b)

Figure 4. (a) The velocity map of design 1; (b) The photo of design 1.

Table 1. The value of the velocity of Figure 4(a).

\begin{tabular}{llllll}
\hline Point & Velocity(m/s) & Point & Velocity(m/s) & Point & Velocity(m/s) \\
\hline$(1)$ & 1.52 & $(6)$ & 0.64 & $(10)$ & 0.77 \\
$(2)$ & 1.13 & $(7)$ & 0.63 & $(11)$ & 0.51 \\
$(3)$ & 1.06 & $(8)$ & 0.57 & $(12)$ & 0.32 \\
$(4)$ & 0.95 & $(9)$ & 0.88 & $(13)$ & 0.31 \\
$(5)$ & 0.87 & & & & \\
\hline
\end{tabular}

The velocity map of design 1 was shown in Figure 4(a). The distribution of these 13 measure points were: point (1) to point (5), the maximum velocity line, which was defined to indicate the location of the maximum velocity in each column; point (6) to point (9), and point (10) to point (13) in these two vortex zones, respectively. Table 1 showed the value of the velocity of Figure 4(a). The average velocity was $\mathrm{V}_{\mathrm{d} 1 \text {,av }}=1.106 \mathrm{~m} / \mathrm{s}$, according to the value in measurement point (1) to point (5). The maximum velocity that appeared in design 1 was $\mathrm{V}_{\mathrm{d} 1 \text {, max }}=$ $1.52 \mathrm{~m} / \mathrm{s}$. Figure 4(b) is the photo of design 1, it showed the flow pattern clearly.

\subsection{Experimental Work of Design 2}

"I" shaped baffle, $S=2.7 \%$ ( $S$ denotes "slope").

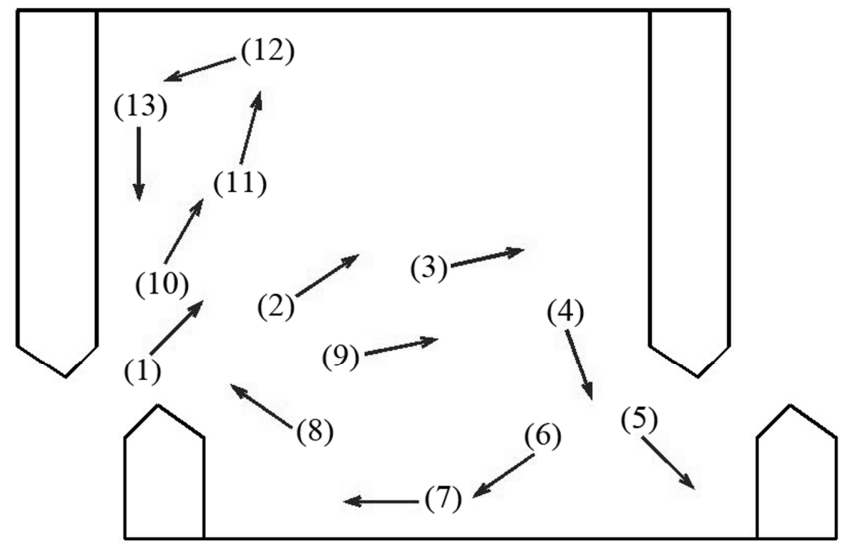

(a)

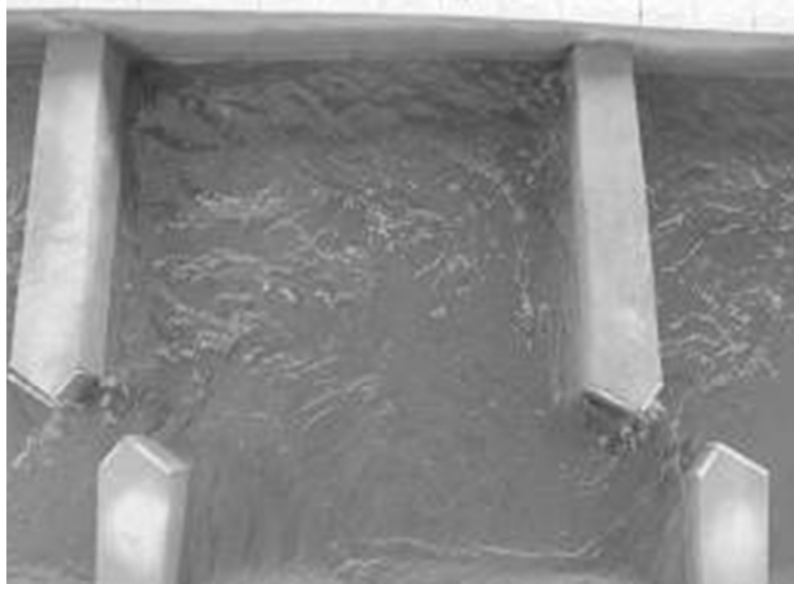

(b)

Figure 5. (a) The velocity map of design 2; (b) The photo of design 2.

Table 2. The value of the velocity of Figure 5(a).

\begin{tabular}{llllll}
\hline Point & Velocity(m/s) & Point & Velocity(m/s) & Point & Velocity(m/s) \\
\hline$(1)$ & 1.26 & $(6)$ & 0.66 & $(10)$ & 0.75 \\
$(2)$ & 1.11 & $(7)$ & 0.62 & $(11)$ & 0.49 \\
$(3)$ & 1.07 & $(8)$ & 0.58 & $(12)$ & 0.34 \\
$(4)$ & 0.82 & $(9)$ & 0.78 & $(13)$ & 0.29 \\
$(5)$ & 0.85 & & & & \\
\hline
\end{tabular}

The velocity map of design 2 was shown in Figure 5(a). The distribution of these 13 measure points were: point (1) to point (5), the maximum velocity line, which was defined to indicate the location of the maximum velocity in each column; point (6) to point (9), and point (10) to point (13) in these two vortex zones, respectively. Table 2 showed the value of the velocity of Figure 5(a). The average velocity was $\mathrm{V}_{\mathrm{d} 2 \text {,av }}=$ $1.022 \mathrm{~m} / \mathrm{s}$, according to the value in measurement point (1) to point (5). The maximum velocity that appeared in design 2 was $\mathrm{V}_{\mathrm{d} 2 \text {, max }}=1.26 \mathrm{~m} / \mathrm{s}$. Figure $5(\mathrm{~b})$ is the photo of design 2, it showed the flow pattern clearly.

\subsection{Experimental Work of Design 3}

"L" shaped baffle, $S=5.4 \%$ ( $S$ denotes "slope").

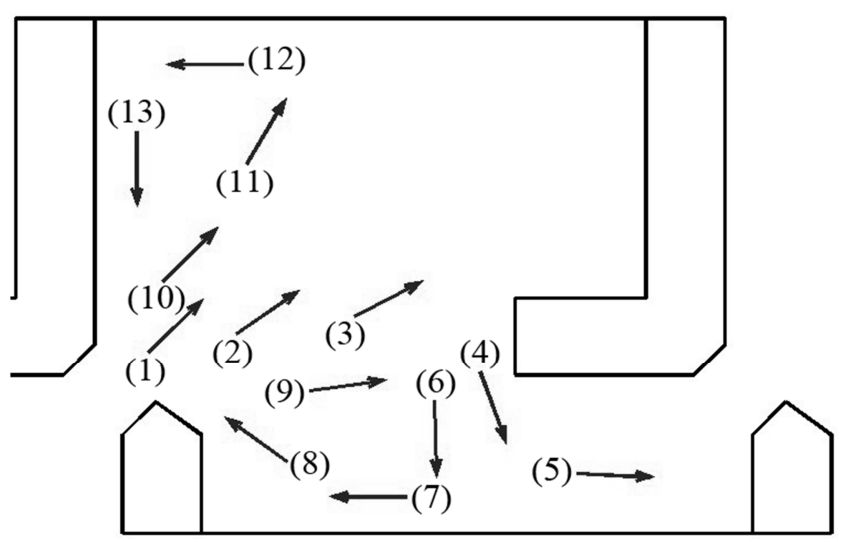

(a) 


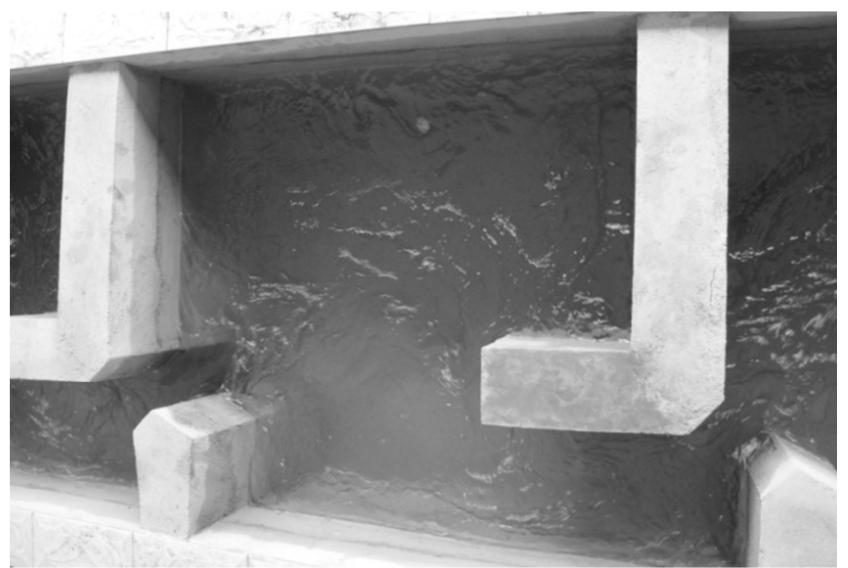

(b)

Figure 6. (a) Thevelocity map of design 3; (b) The photo of design 3.

Table 3. The value of the velocity of Figure 6(a).

\begin{tabular}{llllll}
\hline Point & Velocity(m/s) & Point & Velocity(m/s) & Point & Velocity(m/s) \\
\hline$(1)$ & 1.41 & $(6)$ & 0.59 & $(10)$ & 0.61 \\
$(2)$ & 1.11 & $(7)$ & 0.65 & $(11)$ & 0.35 \\
$(3)$ & 1.01 & $(8)$ & 0.56 & $(12)$ & 0.26 \\
$(4)$ & 0.89 & $(9)$ & 0.82 & $(13)$ & 0.37 \\
$(5)$ & 0.93 & & & & \\
\hline
\end{tabular}

The velocity map of design 3 was shown in Figure 6 (a). The distribution of these 13 measure points were: point (1) to point (5), the maximum velocity line, which was defined to indicate the location of the maximum velocity in each column; point (6) to point (9), and point (10) to point (13) in these two vortex zones, respectively. Table 3 showed the value of the velocity of Figure 6 (a). The average velocity was $\mathrm{V}_{\mathrm{d} 3 \text {,av }}=1.07$ $\mathrm{m} / \mathrm{s}$, according to the value in measurement point (1) to point (5). The maximum velocity that appeared in design 3 was $\mathrm{V}_{\mathrm{d} 3 \text {, } \max }=1.41 \mathrm{~m} / \mathrm{s}$. Figure $6(\mathrm{~b})$ is the photo of design 3 , it showed the flow pattern clearly.

\subsection{Experimental Work of Design 4}

"L" shaped baffle, $S=2.7 \%$ ( $S$ denotes "slope").

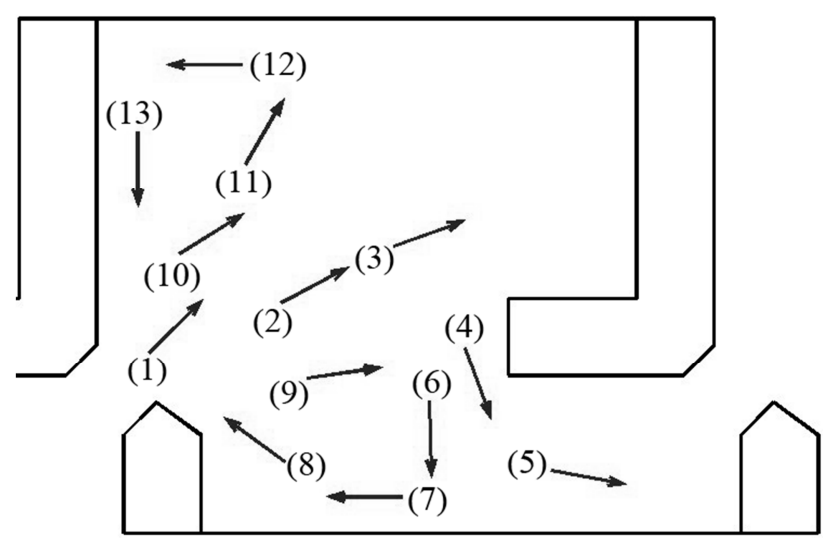

(a)

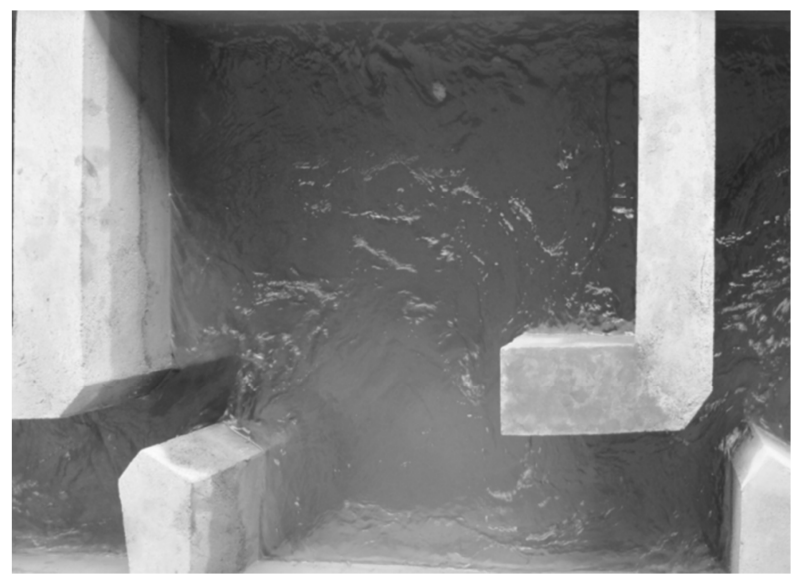

(b)

Figure 7. (a) The velocity map of design 4; (b) The photo of design 4.

Table 4. The value of the velocity of Figure 7 (a)

\begin{tabular}{llllll}
\hline Point & Velocity(m/s) & Point & Velocity(m/s) & Point & Velocity(m/s) \\
\hline$(1)$ & 1.14 & $(6)$ & 0.39 & $(10)$ & 0.65 \\
$(2)$ & 1.03 & $(7)$ & 0.45 & $(11)$ & 0.38 \\
$(3)$ & 0.92 & $(8)$ & 0.36 & $(12)$ & 0.22 \\
$(4)$ & 0.75 & $(9)$ & 0.46 & $(13)$ & 0.25 \\
$(5)$ & 0.76 & & & & \\
\hline
\end{tabular}

The velocity map of design 4 was shown in Figure 7 (a). The distribution of these 13 measure points were: point (1) to point (5), the maximum velocity line, which was defined to indicate the location of the maximum velocity in each column; point (6) to point (9), and point (10) to point (13) in these two vortex zones, respectively. Table 4 showed the value of the velocity of Figure 7 (a). The average velocity was $\mathrm{V}_{\mathrm{d} 4 \text {,av }}=0.92$ $\mathrm{m} / \mathrm{s}$, according to the value in measurement point (1) to point (5). The maximum velocity that appeared in design 4 was $\mathrm{V}_{\mathrm{d} 4 \text {, } \max }=1.14 \mathrm{~m} / \mathrm{s}$. Figure 7 (b) is the photo of design 4 , it showed the flow pattern clearly.

\section{Discussion}

\subsection{Flow Patterns}

Depended on the geometric dimensions of the pools, two different flow patterns had been observed, named flow pattern 1 for "I" shaped baffle (design 1 and design 2), flow pattern 2 for "L" shaped baffle (design 3 and design 4). In both flow patterns, three different regions could be distinguished: a main flow region defined by a high velocity jet, where the maximum velocities in the pool occur, and two low velocity recirculation regions.

For flow pattern 1, the main flow followed a curved path as it crosses the slot, and directly hit the opposite wall. Two low velocity recirculation regions appeared in the two sides of the jet, as Figure 4 (b) and Figure 5 (b) showed.

For flow pattern 2, the main flow first passed the slot, then flowed back after blocking by the "L" shaped baffle. The flow headed down when it meeting the central baffle, and then flowed to the next pool, as Figure 6 (b) and Figure 7 (b) showed. As for these two low velocity recirculation regions, 
they could be explained like this: the flow narrowed by the slot at the entrance, when the obstacle disappeared, the condition of the flow boundary was changed greatly, rapidly varied flows were formed along two sides of the main flow, and then low velocity recirculation regions appeared.

The comparison between Figure 3 (b), Figure 4 (b), Figure 6 (b) and Figure 7 (b) indicated that design 4 was much better than the others, in terms of flow pattern.

\subsection{Velocity}

One of the critical factors that determined the efficiency of a vertical slot fishway design was the velocity near the slot, as the experimental results showed that the maximum velocity appeared in the jet direction behind the slot. Fishuse their burst speed when ascending the slot from one pool to the next.

Table 1-Table 4 showed that the average velocities in the maximum velocity line of these four designs were: $\mathrm{V}_{\mathrm{d} 1 \text {,av }}=1.106$ $\mathrm{m} / \mathrm{s}, \mathrm{V}_{\mathrm{d} 2, \mathrm{av}}=1.022 \mathrm{~m} / \mathrm{s}, \mathrm{V}_{\mathrm{d} 3, \mathrm{av}}=1.07 \mathrm{~m} / \mathrm{s}, \mathrm{V}_{\mathrm{d} 4, \mathrm{av}}=0.92 \mathrm{~m} / \mathrm{s}$, and the maximum velocities were: $\mathrm{V}_{\mathrm{d} 1, \max }=1.52 \mathrm{~m} / \mathrm{s}, \mathrm{V}_{\mathrm{d} 2 \text {, max }}=1.26$ $\mathrm{m} / \mathrm{s}, \mathrm{V}_{\mathrm{d} 3 \text {, max }}=1.41 \mathrm{~m} / \mathrm{s}, \mathrm{V}_{\mathrm{d} 4, \text { max }}=1.14 \mathrm{~m} / \mathrm{s}$, respectively. Compared with design 1, the average velocity of design 2 to 4 were cut down: $7.6 \%, 3.3 \%, 16.8 \%$; and the maximum velocity of design 2, 3, and 4 were cut down: $0.26 \mathrm{~m} / \mathrm{s}, 0.11 \mathrm{~m} / \mathrm{s}$, and 0.38 $\mathrm{m} / \mathrm{s}$, respectively. The results pointed out that design 4 was much better than the others, in terms of velocity.

\section{Conclusions}

The efficiency of a vertical slot fishway design is determined by the agreement between its hydraulic characteristics and the requirements and swimming performance of the target species. A hydraulic parameter which is a mainly factor in order to evaluate the migratory efficiency is the velocity in the fishway.

The discussion part of this paper indicates that the central baffle are not an effective way to cut down the velocity in the fishway, but it can smooth the flow pattern; Simultaneously, slope have significant impact on hydraulic characteristics like velocity and flow pattern in the fishway. Thus, it is recommended that a vertical slot fishway with a slope of less than $5.4 \%$ according to the experimental results. Of the four designs studied, design 4 in this paper could be an example for vertical slot fishway design, in terms of velocity and flow pattern.

\section{Acknowledgements}

This study has been supported by Education Department of Sichuan Province (2017-1399) and Sichuan Agricultural University (03571673, 04051812, and 06509001).

\section{References}

[1] Gross M R, Coleman R M, Mcdowall R M. Aquatic Productivity and the Evolution of Diadromous Fish Migration [J]. Science, 1988, 239 (4845): 1291-3.

[2] Dugan P J, Winemiller K O. Fish Migration, Dams, and Loss of Ecosystem Services in the Mekong Basin [J]. Ambio, 2010, 39 (4): $344-348$.

[3] Mao X. Study of Fish-friendly Fishway Hydraulics in Mountainous Rivers of Southwest China [D]. Sichuan University, 2015 (in Chinese).

[4] Mao X, FU J J, TUO Y C, et al. Influence of structure on hydraulic characteristics of T shape fishway [J]. Journal of Hydrodynamics, 2012, 24 (5): $684-691$.

[5] Mao X, Li J, Yi W M, et al. Study on Optimizing the Structure of the Fishway [J]. Journal of Sichuan University (Engineering Science Edition), 2011, 43 (S1): 54-59 (in Chinese).

[6] Fuentes-Pérez J F, Sanz-Ronda F J, Azagra A M D, et al. Non-uniform hydraulic behavior of pool-weir fishways: A tool to optimize its design and performance [J]. Ecological Engineering, 2016, 86: 5-12.

[7] Schwalme K, Mackay W C, Lindner D. Suitability of Vertical Slot and Denil Fishways for Passing North-Temp. [J]. Canadian Journal of Fisheries \& Aquatic Sciences, 2011, 42 (11): $1815-1822$.

[8] Rajaratnam N, Vinne G V D, Katopodis C. Hydraulics of Vertical Slot Fishways [J]. Journal of Hydraulic Engineering, 1986, 112 (10): 909-927.

[9] Clay C H. Design of Fishways and Other Fish Facilities [J]. Boca Ranton Edition Isbn, 1995.

[10] Bell M C. Fisheries Handbook of Engineering Requirements and Biological Criteria [J]. Reports, 1991.

[11] Rodríguez T T, Agudo J P, Mosquera L P, et al. Evaluating vertical-slot fishway designs in terms of fish swimming capabilities [J]. Ecological Engineering, 2006, 27 (1): 37-48. 